\title{
SPECIAL HOUSING FOR PARAPLEGICS
}

\author{
By A. TRICOT, M.D. \\ Centre de Traumatologie et de Réadaptation, Hôpital Universitaire Brugmann, Brussels, \\ Belgium
}

DuRING the last few years, Public Authorities in Belgium have become more and more conscious of the problems of social reintegration of the physically disabled.

The physically disabled, paraplegics among others, have secured the attention of the Superior Council of the 'Institut National du Logement' and this institute has undertaken the study of the special needs in the matter of housing of this category of disabled persons. From this study, we are of the opinion that we must adopt a housing policy which facilitates the social re-integration of the disabled by giving them housing adapted to their special needs, as this is an important condition for their re-integration from both a social and a family point of view.

It was agreed from the beginning that it was very important to avoid any type of segregation of the disabled and that it was, therefore, essential to avoid any sort of grouping of the disabled and their families. It was also considered important to house rehabilitated disabled persons in important urban centres where they would have the possibility of professional resettlement.

The population amidst which special houses or apartments for disabled persons are to be built should be informed about the causes and consequences of neuromotor paralysis, and a co-ordinated action of public authorities and specialized medical groups, on the one hand, and representatives of disabled persons, on the other, is necessary to enumerate in a precise way the particular requirements of housing and to bring adequate solutions to the present problems.

The first step in this study was thus directed towards the social, medical and legal aspects of the problem of reintegration of the physically disabled.

One can estimate the number of physically disabled persons at present in Belgium as 312,000. This is approximately 3 per cent. of the total population of the country. Amongst these 312,000 cases a number of 10,400 cases were specially examined in the light of the records established by the 'Fonds des Handicapés'. A little over 3 I per cent. of these 10,400 cases present impairment of the two lower limbs.

This has allowed us to assume that, for these 312,000 cases of physically disabled, one can reasonably estimate that at least about 13,500 are obliged to use a wheelchair.

Most of these people confined to wheelchairs live in big urban centres or in the proximity of cities.

After having thus given an approximation of the total number of locomotor disabled persons to be taken into consideration, the survey included the structure of the families where one of the members is disabled, and the results of this survey seem to be particularly important.

In a group of 1763 disabled persons with a disability of more than 60 per cent. there are over 37 per cent. single, I4 per cent. couples without children where one or both members are disabled, 32 per cent. couples with one or several disabled 
children, and 17 per cent. disabled couples with non-disabled children. If one compares the number of disabled persons living alone with the number of nondisabled persons living alone, one is surprised to find that 37 per cent. disabled are living alone as compared 25 per cent. non-disabled persons. It is certain that this important fact has an influence on the housing plan.

A general public inquiry regarding the social reintegration of the disabled was made. Two questions were set forth; the first: 'Have you any major objection to living in the same building, perhaps even on the same floor, as a physically disabled person confined to a wheelchair, this person being nevertheless capable of leading an independent life.'

The second question, after giving explanations about the nature of the disability and degree of independence of the disabled was "Do you wish to modify your previous answer?"

We were able to establish the following facts from the results of this inquiry: about 55 per cent. of the people questioned had no major objections to the presence of disabled persons as co-tenants, but it is the single person under 30 or married couples without children who are preferred, whereas unfavourable opinions were most frequently encountered regarding old people living alone or married couples with children.

It must be noted that the general public is unaware of the real aspects of the problems and that the use of a wheelchair often brings about the idea of polio and, therefore, the fear of possible contamination, while most people ignore completely the existence of paralysis resulting from other spinal cord lesions or diseases resulting in senso-motor paraplegia. I think it is useful to summarize the reasons put forward to justify a negative attitude. In the order of decreasing importance, these reasons are: poliomyelitis and fears of contamination, a sight considered unwholesome for children, a feeling of embarrassment of simply pity, fear that from the presence of a disabled person would arise the duty of rendering services for the neighbours, and finally those who are opposed to the idea of living together with a disabled person on principle.

From all this, it would appear that information to the public is of paramount importance and this is proved by the increase of favourable answers (from 60 to 70 per cent.) after the explanations given by the inquirer.

From this part of the survey, we may conclude that:

I. There does not seem to exist any major objection to the social integration of the disabled in the matter of housing on the part of the public.

2. The opposition to the idea expressed at first by able-bodied persons disappeared partly after correct information.

3. Domestic integration of the disabled would be easier in a young and lively environment.

4. One should avoid mixing families of disabled persons with families of more than three children, even if the family of the disabled person is itself a large one.

5. It is important that the disabled persons be independent and not have to rely, even occasionally, on the goodwill of their neighbours.

6. One should avoid any concentration of old people in buildings involving appartments for disabled persons.

7. In these buildings, the physically disabled must constitute a minority group.

While the total number of physcially disabled persons represents 3 per cent. of 
the population in Belgium, this figure should be considered as the minimum, the maximum being under 9 per cent. i.e. about three times the value of the minimum.

This social aspect of the survey was completed by data on legislation for the protection and indemnification of disabled persons and on the medical aspects of their rehabilitation.

From the first part of the enquiry, the 'Institut National du Logement' has been able to formulate conclusions regarding the conditions of housing situations for disabled persons and the conditions facilitating their social reintegration.

An ergonomic study was undertaken simultaneously to survey the technical limits of housing for physically disabled persons.

The ergonomic study surveyed the types of wheelchairs most commonly used, the space necessary for the use of these wheelchairs and special adjustments necessary such as handrails, etc.

The study of the technical data allowed us to formulate instructions concerning the planning of access to the buildings, access to the elevators, the dimensions of the doors,openings and exits, the bathroom and sanitary equipment,kitchen equipment, the floor coverings and furniture, electrical set-up and its accessories, and finally the general services. It would be beyond the scope of this paper to go into all the details of these different points, these being technical problems concerning architects in particular; but I think it is useful to summarise the general conclusions of the second part of the survey

I. A disabled person's apartment does not necessarily have to be more spacious than an ordinary apartment. It is not the size that matters but its distribution and adjustment.

2. If a disabled person's apartment is convenient for an able-bodied person, the reverse is not necessarily true, and this has nothing to do with either the cost or class of the apartment.

The two practical considerations allow us to say that it is possible to include in a building special apartments amongst ordinary apartments, on the condition that the building as whole be designed to function by special means of access.

The necessary special means of access will certainly be convenient for a normal apartment; it is the clearance space which has to be larger and this applies to the whole building.

The Superior Council of the 'Institut National du Logement' having been informed of the conclusions of this survey, took the immediate decision to promote the creation of a first experimental construction including eight apartments adapted to the special needs for neuro-motor disabled persons. The experiment was confined to the adjustment of the plans of part of a building of 12 floors with altogether 88 apartments; that is to say about 9 per cent. were specially adapted apartments.

This block is part of a set of four buildings situated in a huge park which offers important parking facilities in the centre of which a school has been set up.

Each building consists of $\mathrm{I} 2$ floors, and three buildings are already erected and inhabited; the fourth which has been planned will be finished this year.

For technical reasons of adaptation, it is only from the fourth floor that apartments for disabled persons have been modified.

There are three types of apartments: three flats with one bedroom suitable for one or two people; two flats with three bedrooms for five people and three flats with two bedrooms convenient for three or four people.

They consist, apart from the bedrooms, of a living-room with adjacent 
kitchen, a toilet reserved for the disabled person, a second toilet, a bathroom, a hall, two terraces, and a cellar for the whole floor.

The modifications in relation to the non-adapted apartments lie essentially in increase in moving space and clearance (corridors, exits, etc.)

For example, one has taken the care to position the door of one of the rooms in order to increase the moving space available for the wheelchair; the entrance hall has been widened, suspended cupboards have been planned, the kitchen and its equipment have been adapted, the bathroom has been altered in its layout by setting up a toilet which is easily accessible in a wheelchair, whilst the bath is provided with a seat which permits the disabled person to transfer himself from the wheelchair to the bath which is equipped with handrails.

One must nevertheless note that these modifications could not have been effected without bearing in mind the necessary points resulting from the type of construction, these necessary points being identical for the four buildings of the group.

This experimental scheme will be situated in the immediate proximity of the Centre de Traumatologie et de Readaptation which can give without delay all the specialised nursing which may become necessary, to the disabled living there.

Finally, the 'Institut National du Logement' foresees a considerable widening of its experience by having already carried out projects of the same order in other towns of the country in Marcinelle, Liège, Antwerp and probably in Bruges.

But, besides this conception of housing for physically disabled persons, it was necessary to consider the creation of a 'sheltered-work' community reserved for severer cases of disability. In several of the latter cases, it was obvious that the severity of their disability renders professional rehabilitation in a normal way very difficult.

That is the reason why the idea of the creation of a sheltered work community has been retained, although the latter infers the idea of segregation which we wish to avoid at all costs. Also, this concentration of disabled persons in such an area has been delayed by foreseeing its site in an area of one-family lodgings to be set up in the very near proximity of Brussels. This is still only an idea which has met with very lively interest in various circles. This permits us to hope for the quick realisation of the project. Situated in the immediate proximity of an industrial block, the site offers the guarantee of a varied supply of work for the sheltered workshop, the first plans have already been traced.

Forty lodgings have been foreseen. They are bungalows spread out in four groups around two central buildings: a medico-social centre and a sheltered workshop.

Each group of bungalows includes a common garage (this being more economical), a common central heating, a block of four lodgings for one person and six family units.

Access of cars is effected by a private roadway, whilst a sports field for archery, basket-ball and so forth, has been visualised.

The four lodgings for one person give access to a common hall, in which are fitted letterboxes, individual cupboards which allow tradesmen to deposit their goods and finally a refuse-bin emptier.

Each of these lodgings for single persons includes a small entrance-hall, a living-room, a kitchenette, a bedroom separated from the living-room by a sliding door and a bathroom with sanitary equipment opening out on to the entrancehall and the bedroom. 
The bungalows for married couples are adjusted to house five people and include an entrance-hall, a living-room, an adapted kitchen with a counter for passing dishes and an adjacent table, three bedrooms, two toilets and two bathrooms.

We have been particularly pleased to tell you of the realisations of social housing in Belgium, realisations which are relative to the housing of the physically disabled, mainly paraplegics. We hope that these first achievements will permit us to solve quickly the problems of the social regrouping of paraplegics, as otherwise all the efforts entailed by their rehabilitation would remain incomplete.

We thank most sincerely the head staff of the 'Institut National du Logement' for having given us the relevant documents, and in particular the General Secretary Mr. Crappe, and Mr. De Beuyker, delegate of mission at the Institute, who carried out the enquiry.

\title{
THE MARRIED LIFE OF PARAPLEGICS AND TETRAPLEGICS
}

\author{
L. Guttmann, C.B.E., M.D., F.R.C.P., F.R.C.S. \\ National Spinal Injuries Centre, \\ Stoke Mandeville Hospital, Aylesbury, Bucks., England
}

IT is the aim of everyone concerned with the social resettlement of spinal cord sufferers to return as many of them as possible to their homes to live a near normal life within the community. Naturally, one would expect that a disablement of a magnitude such as paraplegia and tetraplegia would set up in its wake difficult problems in the domestic resettlement of these severely disabled people, particularly in their marital adjustment. This is doubtless true, to a certain extent. Nevertheless, it is an undeniable fact that many subjects who were already married at the time of their spinal cord injury or disease have continued their married life successfully for many years, and others who were single have started their married life after having become paraplegics or tetraplegics.

Major statistical surveys on the marital life of a particular number of paraplegics and tetraplegics do not exist, apart from one published in 1962 by Comarr of the Spinal Unit at Long Beach Veterans Hospital, U.S.A., on 859 paraplegic and tetraplegic veterans of the U.S. Army.

In the present paper, a statistical survey is presented on the marital status of I505 living traumatic paraplegics and tetraplegics of marriageable age treated at Stoke Mandeville, 527 of whom were ex-service pensioners. There were I3I6 men and 189 women.

The marital status of these people before admission is given in Table I, showing 674 ( 44.8 per cent.), of whom 69 were women, married and living with their partners. This figure includes marriages both before and after injury, the great majority being after injury. A total of 777 ( $5 \mathrm{I} \cdot 8$ per cent.), amongst them 99 women, were single, and 15 not included in the figure of 777 were known to be cohabiting. Before admission 17 more were divorced or separated and 22 were widowed.

Out of the 777 single ones in Table I 302 married after admission, the majority (267) being paraplegics. Table II shows the division of complete and incomplete lesions amongst the married paraplegics and tertaplegics of this group. The majority of paraplegic men who married normal women were compete lesions (I4I) 